\title{
A PROSPECTIVE RANDOMIZED STUDY TO COMPARE DEXMEDETOMIDINE WITH CLONIDINE AS AN ADJUVANT TO BUPIVACAINE IN SUPRACLAVICULAR BRACHIAL PLEXUS BLOCK
}

\author{
Pavani Kalyanam¹, Madhavi Julakanti², B. Shyam Babu³, Molli Kiran4, C. G. Raghuram ${ }^{5}$ \\ ${ }^{1}$ Associate Professor, Department of Anesthesiology \& Critical Care, Osmania Medical College, Hyderabad, Telangana, India. \\ ${ }^{2}$ Assistant Professor, Department of Anesthesiology \& Critical Care, Osmania Medical College, Hyderabad, Telangana, India. \\ 3 Junior Resident, Department of Anesthesiology \& Critical Care, Osmania Medical College, Hyderabad, Telangana, India. \\ ${ }_{4}^{4}$ Junior Resident, Department of Anesthesiology \& Critical Care, Osmania Medical College, Hyderabad, Telangana, India. \\ 5 Professor \& HOD, Department of Anesthesiology \& Critical Care, Osmania Medical College, Hyderabad, Telangana, India.
}

ABSTRACT: BACKGROUND: Various agents have been used as adjuvants to prolong the duration of action and improve efficacy of local anaesthetic agents. Recently, alpha2 agonists have become the focus of interest as adjuvants to local anaesthetics.

AIM: To compare the onset time, duration of sensory and motor block and duration of analgesia when Clonidine or Dexmedetomidine is added to Bupivacaine in supraclavicular brachial plexus block.

METHODS: Sixty ASA Grade I and II patients scheduled for elective forearm and hand surgeries under supraclavicular brachial plexus block were divided into two equal groups in a randomized fashion. Group C received Bupivacaine 0.25\% (35cc)+Clonidine $1 \mu \mathrm{g} / \mathrm{kg}$ and Group D received Bupivacaine $0.25 \%$ (35cc)+Dexmedetomidine $1 \mu \mathrm{g} / \mathrm{kg}$. Onset and duration of sensory and motor block, and duration of analgesia were compared.

STATISTICAL ANALYSIS USED: Qualitative data- Chi Square test; Quantitative data- Unpaired student's ' $t$ ' test.

RESULTS: The onset of sensory block was earlier in Group D $(8.53 \pm 0.72)$ than in Group C $(8.18 \pm 0.55)$ which was statistically significant $(\mathrm{p}<0.05)$.There was no significant difference in onset of motor block between the two groups. Duration of sensory block and motor block was $331.43 \pm 6.693$ and $271.436 .69 \mathrm{~min}$, respectively, in group C, while it was $395.93 \pm 12.55$ and $335.93 \pm 12.55 \mathrm{~min}$ respectively in group D which was statistically significant $(\mathrm{p}<0.05)$. The duration of analgesia (Time to requirement of rescue analgesia) in group C was $407.06 \pm 10.90 \mathrm{~min}$, while in group D was 497.0610 .90 and this difference was significant (p <0.001). Patients in Group D were more sedated than those in Group C $(\mathrm{p}<0.001)$. There was no significant difference in hemodynamics between the two groups.

CONCLUSION: Dexmedetomidine when added to Bupivacaine in supraclavicular brachial plexus block enhanced the duration of sensory and motor block and also the duration of analgesia when compared with Clonidine.

KEYWORDS: Bupivacaine, Clonidine, Dexmedetomidine, Brachial Plexus block

HOW TO CITE THIS ARTICLE: Pavani Kalyanam, Madhavi Julakanti, B. Shyam Babu, Molli Kiran, C. G. Raghuram. “A Prospective Randomized Study to Compare Dexmedetomidine with Clonidine as an Adjuvant to Bupivacaine In Supraclavicular Brachial Plexus Block". Journal of Evolution of Medical and Dental Sciences 2015; Vol. 4, Issue 88, November 02; Page: 15289-15297,

DOI: $10.14260 /$ jemds/2015/2174.

INTRODUCTION: The supraclavicular block of the brachial plexus has the reputation of providing excellent anaesthesia for upper limb surgery. Sometimes the duration falls short of the total duration of surgery in case of long surgical procedures resulting in the need to convert the procedure to general anaesthesia.

$\alpha-2$ adrenergic receptor agonists as adjuvants to local anaesthetics have been the focus of interest for their sedative, analgesic, perioperative sympatholytic and cardiovascular stabilizing effects with reduced anaesthetic requirements.(1) Clonidine and Dexmedetomidine both are $\alpha$ -2 adrenoceptor agonists.

Since 1980s Clonidine has been used as an adjuvant to local anaesthetics in various regional techniques to extend the duration of block.(2)

Financial or Other, Competing Interest: None.

Submission 08-10-2015, Peer Review 09-10-2015,

Acceptance 20-10-2015, Published 30-10-2015.

Corresponding Author:

Dr. K. Pavani,

Flat No. 301B, Essel Classic, Phase III,

KPHB, Kukatpally, Hyderabad, 500072.

E-mail: pavanikalyanam67@gmail.com

DOI:10.14260/jemds/2015/2174.
It has been proved that Clonidine improves the quality and duration of local anaesthetic nerve blocks. $(3,4,5)$

Dexmedetomidine is approximately eight-times more selective towards the $\alpha-2$ adrenoceptor than Clonidine.(6) In previous clinical studies, intravenous Dexmedetomidine resulted in significant opioid sparing effects as well as a decrease in inhalational anaesthetic requirements. (7) Dexmedetomidine has also been shown to prolong the duration of block and post-operative analgesia when added to local anaesthetic in various regional blocks. ${ }^{(8-11)}$

In this study, we compared Clonidine and Dexmedetomidine as adjuvants to Bupivacaine in supraclavicular brachial plexus block with respect to the onset and duration of sensory and motor block as well as duration of analgesia.

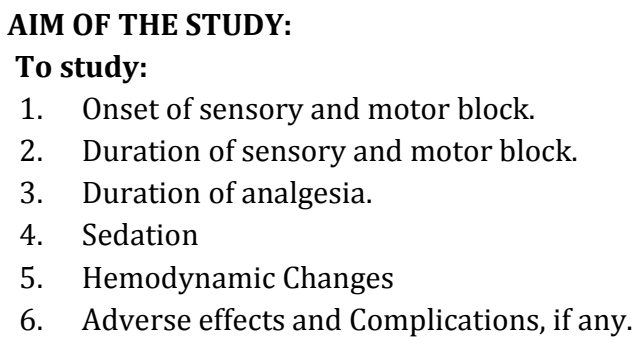


METHODS: After the Institutional Ethics Committee approval, a prospective, randomized study has been done in sixty patients of either sex aged between 15 years and 60 years and of physical status ASA grade 1 and ASA grade 2 undergoing elective forearm and hand surgeries.

The patients were randomly divided in to 2 groups i.e. group $\mathrm{C}$ and $\mathrm{D}$ as per computerized random number table and each group had 30 patients.

\section{INCLUSION CRITERIA}

- Patients aged between 15 yrs and 60 yrs

- Physical status ASA grade I \& II

- Scheduled for elective forearm and hand surgeries.

\section{EXCLUSION CRITERIA:}

- Patient's refusal

- Traumatic nerve injury

- Pneumothorax

- Local infection

- Bleeding disorders or patient on anticoagulant therapy

- Known allergy to local anaesthetic agents or study drugs.

Patients were evaluated prior to surgery and relevant investigations done before assessment. Patient was informed about the anaesthesia procedure, drugs that would be used, its effects and side effects. Written informed valid consent was obtained.

\section{PREPARATION OF SOLUTION:}

For Group C: To $35 \mathrm{ml}$ of Inj. Bupivacaine (0.25\%), Inj. Clonidine $1 \mu \mathrm{g} / \mathrm{kg}$ was added using insulin syringe.

For Group D: To $35 \mathrm{ml}$ of Inj. Bupivacaine (0.25\%), Inj. Dexmedetomidine $1 \mu \mathrm{g} / \mathrm{kg}$ was added using insulin syringe.

PROCEDURE: Patient was taken on operation table. Starvation period was confirmed Intravenous access was secured with $18 \mathrm{G}$ cannula on non-operated hand and IV Ringer Lactate was started.

Following monitors were connected to the patients in the operating room;

1. Pulse oximeter.

2. Non-invasive blood pressure.

3. ECG.

Baseline parameters were recorded i.e.

- $\quad$ Pulse rate (PR)

- Systolic blood Pressure (SBP), Diastolic blood Pressure (DBP)

- $\quad \mathrm{SpO} 2$ on room air.

$\mathrm{O}_{2}$ was given at rate of 4 litre / min through Hudson's mask.

All the necessary equipment and drugs needed for administration of general anaesthesia and for resuscitation were kept ready in order to manage in case of a failed block.

Under aseptic precautions brachial plexus block was performed by supraclavicular approach using peripheral nerve locator. During injection, negative aspiration was done after every $5 \mathrm{ml}$ to avoid intravascular injection.
Pulse rate (PR), systolic blood pressure (SBP), diastolic blood pressure (DBP), and oxygen saturation $\left(\mathrm{SPO}_{2}\right)$ were recorded at $0,5,15,30,60$ minutes in the first hour and every hour thereafter up to 6 hours. Patients were monitored up to 24 hours.

\section{PARAMETERS OBSERVED:}

- Onset and duration of sensory blockade.

- Onset and duration of motor blockade.

- Duration of analgesia.

- Sedation.

- Hemodynamics.

- Adverse effects and complications, if any.

\section{ASSESSMENT:}

Onset of Sensory Blockade: Sensory block was assessed as loss of pinprick sensation using the 23G hypodermic needle. Onset time is the time from the completion of injection of drug to first loss of pinprick sensation.

Onset of Motor Blockade: Onset time of motor blockade was defined as the time from the completion of injection of study drug to first loss of motor power of any of the four nerves.

Duration of Sensory Blockade: Duration of sensory blockade was the time from the onset of sensory blockade to complete recovery of sensation in all the areas of nerve distribution.

Duration of Motor Blockade: Duration of motor blockade was the time from the onset of motor blockade to complete recovery of motor power.

Duration of Analgesia: Duration of post-operative analgesia was taken till the time patient asked for rescue analgesia.

Inj. Paracetamol 1gram was given by slow IV infusion as a rescue analgesic for post-operative pain.

If supplementation with IV analgesia or general anaesthesia was required due to inadequate/ partial block, the case was not included in the study.

\section{SEDATION:}

Sedation was assessed by modified Ramsay sedation score.(12)

1. Anxious and agitated or restless or both

2. Co-operative, oriented and tranquil

3. Drowsy but responding to commands

4. Asleep, brisk response to light glabellar tap

5. Asleep, sluggish response to light glabellar tap

6. Asleep, no response to light glabellar tap

Adverse Effects: Patients were monitored for any sign of central nervous system toxicity (tingling and numbness in perioral region, tinnitus, convulsions, loss of consciousness) and cardiovascular toxicity (like changes in heart rate, arrhythmias, hypotension and hypertension).

Complications: Pneumothorax, hematoma at the site of injection and Horner's syndrome were observed for.

Postoperatively, Patients were shifted to PACU. $\mathrm{SpO}_{2}$, Pulse rate and BP were recorded. All patients received oxygen through Hudson's mask at the rate of 4 liters/min 
RESULTS: Overall 60 patients were studied in age group of 15 - 60 years in group C and group D.

Demographic Variables: The difference in age, sex and weight distribution between the two groups was not statistically significant. ( $\mathrm{p}$ value $>0.05$

DISCUSSION: Supraclavicular block with local anaesthetics provides excellent operating conditions with good muscle relaxation, but the duration of analgesia is rarely maintained for more than 4-6 hours even with the longest acting local anaesthetics (Bupivacaine, Ropivacaine and LevoBupivacaine). Continuous infusion of local anaesthetics into brachial plexus sheath requires an infusion pump and has potential for cumulative toxicity and unpredictable variability in absorption. Various studies have shown that addition of adjuncts like Clonidine and Dexmedetomidine in local anaesthetic solution in peripheral nerve blocks prolonged the duration of anaesthesia and analgesia.

Since 1980s Clonidine has been used as an adjuvant to local anaesthetics in various regional techniques to extend the duration of block. There have been four proposed mechanisms for the action of Clonidine in peripheral nerve blocks. These mechanisms are centrally mediated analgesia, $\alpha-2$ adrenoceptor mediated vasoconstrictive effects, attenuation of inflammatory response and direct action on peripheral nerve.(13)

The direct action of Clonidine on the nerve can be explained on the basis of a study conducted by Dalle et al.(14) They proposed that Clonidine, by enhancing activitydependent hyperpolarisation generated by the $\mathrm{Na} / \mathrm{K}$ pump during repetitive stimulation, increases the threshold for initiating the action potential causing slowing or blockage of conduction.

Casati et al.(15) observed in their study that adding 1 microgram $/ \mathrm{kg}$ Clonidine to $20 \mathrm{ml}$ of Ropivacaine $0.75 \%$ for axillary brachial plexus anaesthesia provided a 3 hour delay in first analgesic request postoperatively, without clinically relevant effects on the degree of sedation and cardiovascular homeostasis.

Therefore, Clonidine was used in a dose of $1 \mu \mathrm{g} / \mathrm{kg}$ in this study.

Kosugi et al.(16) in their study found that high concentrations of Dexmedetomidine inhibit CAPs in frog sciatic nerves without $\alpha-2$ adrenoceptor activation. Their result showed that Dexmedetomidine reduced the peak amplitude of CAPs reversibly and in a concentrationdependent manner.

There are very few human studies, i.e. greater palatine and axillary brachial plexus nerve blocks have subsequently demonstrated that increased duration of sensory blockade can be achieved by adding Dexmedetomidine to bupivacaine and levobupivacaine, respectively

Swami SS et al.(11)(2012) compared Dexmedetomidine $(1 \mu \mathrm{g} / \mathrm{kg})$ and Clonidine $(1 \mu \mathrm{g} / \mathrm{kg})$ as an adjuvant to local anaesthesia in supraclavicular brachial plexus block and they concluded that Dexmedetomidine when added to local anaesthetic in supraclavicular brachial plexus block enhanced the duration of sensory and motor block and also the duration of analgesia without any side effects.
After reviewing above literature, Dexmedetomidine was used in a dose of $1 \mu \mathrm{g} / \mathrm{kg}$ in this study.

A volume of $35 \mathrm{ml}$ of $0.25 \%$ bupivacaine was taken as this volume was associated with a more complete spread for brachial plexus block without any risk of local anaesthetic related systemic toxicity as observed by Swami SS et al.(11) in their study.

Our study was conducted at a tertiary care centre after institutional ethical committee approval. The study population included 60 ASA I and II patients undergoing elective forearm and hand surgeries.

These patients were randomly divided into two groups; group C and group D, of 30 patients each as per computer generated randomization.

Group C $(\mathrm{n}=30)$ : received supraclavicular brachial plexus block with $0.25 \%$ bupivacaine $(35 \mathrm{ml})+$ Inj. Clonidine $1 \mu \mathrm{g} / \mathrm{kg}$

Group D $(n=30)$ : received supraclavicular brachial plexus block with $0.25 \%$ bupivacaine (35 ml)+Inj. Dexmedetomidine 1 $\mu \mathrm{g} / \mathrm{kg}$.

\section{RESULTS OBTAINED IN THE STUDY ARE AS FOLLOWS:}

1. DEMOGRAPHIC VARIABLES: The two groups were comparable with respect to age, weight, sex distribution, ASA status and duration of surgery

2. CHARACTERISTICS OF SENSORY BLOCK: In the present study, sensory block onset time was defined as the time from the completion of injection of drug to first loss of pinprick sensation in any of the dermatomes.

Onset of sensory blockade was $8.53( \pm 0.72)$ minutes in group C and $8.18( \pm 0.55)$ minutes in group D. This difference was statistically significant $(\mathrm{p}<0.05)$

The mean duration of sensory blockade was 331.43( \pm 6.693$)$ minutes in group $\mathrm{C}$ and $395.93( \pm 12.55)$ minutes in group D. This difference was statistically significant $(\mathrm{p}<0.05)$. Thus; Dexmedetomidine prolonged the duration of sensory blockade compared to Clonidine.

3. CHARACTERISTICS OF MOTOR BLOCK: In the present study, motor block onset time was defined as the time from the completion of injection of drug to first loss of motor power.

Onset of motor blockade was $9.88( \pm 0.55)$ minutes in group $C$ and $10.20( \pm 0.73)$ minutes in group D. Thus, the onset of motor block was faster in $\mathrm{C}$, but this difference was not quite statistically significant $(p>0.05)$.

4. DURATION OF ANALGESIA: The mean duration of analgesia was $407.06 \pm 10.90$ minutes in $C$ group, while in D group; it was $497.06 \pm 10.90$ minutes and the difference was statistically significant between the two groups ( $p<0.001)$. Thus; Dexmedetomidine increased the duration of analgesia compared to Clonidine.

SEDATION: Higher sedation score was observed in patients belonging to Group D than those of Group C but all patients were arousable. No patient required assistance for airway maintenance. 
5. HEMODYNAMICS: The statistical analysis by student's unpaired ' $\mathrm{t}$ ' test showed that there was no significant difference in pulse rate, systolic blood pressure, diastolic blood pressue, Oxygen saturation between the two groups $(\mathrm{p}>0.05)$.

6. SIDE EFFECTS/ COMPLICATIONS: In the present study, any side effect like bradycardia, hypotension, nausea, vomiting etc. was not observed. Also, complications like pneumothorax, hematoma etc. were not seen in any of the group.

The following studies substantiate the results of our study: In 2012, Swami SS et al.(11) found that onset of sensory block was faster in Dexmedetomidine group than in Clonidine group, but this difference was not statistically significant $(p=0.083)$. There was no statistically significant difference in onset of motor block between the Clonidine group and Dexmedetomidine. Mean duration of sensory and motor block was more in Dexmedetomidine group compared to Clonidine group.

Baseline haemodynamic parameters were comparable in both groups. Significantly lower pulse rate was observed at 60,90 and $120 \mathrm{~min}$, but not less than 60 beats/min, in Group D as compared with Group C $(\mathrm{p}<0.001)$. Systolic and diastolic blood pressure were found to be significantly lower than baseline from 30 to $120 \mathrm{~min}$ in Group D as compared with Group C $(\mathrm{P}<0.001)$. No treatment was required for this fall in blood pressure. The haemodynamic parameters were comparable at the end of $180 \mathrm{~min}$.

No side-effects (nausea, vomiting, dry mouth) were reported during the first $24 \mathrm{~h}$ in the post-operative period in both the groups.

Ammar AS et al.(17) compared bupivacaine (0.33\%$30 \mathrm{cc})$ alone or combined with Dexmedetomidine $(0.75 \mu \mathrm{g} / \mathrm{kg})$ in infraclavicular block.They found shorter time to onset of sensory and motor blockade, longer duration of sensory and motor blockade in Dexmedetomidine group.

Kaygusuz $\mathrm{K}$ et al.(18) studied effects of adding Dexmedetomidine $(1 \mu \mathrm{g} / \mathrm{kg})$ to levobupivacaine $(0.5 \%)$ in axillary brachial plexus block. They observed that sensory block onset time was shorter in Dexmedetomidine group and duration of sensory and motor block was longer (in Dexmedetomidine group compared to levobupivacaine alone.

No side-effects (Nausea, vomiting, dry mouth) were reported during the first $24 \mathrm{~h}$ in the post-operative period in both the groups.

Agarwal S et al.(19) conducted a study to determine the role of Dexmedetomidine ( $100 \mu \mathrm{g}$ ) added to $30 \mathrm{ml}$ of 0.325 $\%$ of bupivacaine in supraclavicular block. They observed that the onset time for sensory and motor block was significantly shorter in Dexmedetomidine group as compared to bupivacaine alone, while the duration of sensory and motor block was significantly longer in Dexmedetomidine group. They observed that heart rate levels in Dexmedetomidine group were significantly lower ( $\mathrm{P}<0.001)$ compared to bupivacaine alone except for the initial recordings at $0,5,10$, and $15 \mathrm{~min}$. SBP and DBP levels in Dexmedetomidine group at 15, 30, 45, 60, 90 and $120 \mathrm{~min}$ were significantly lower than bupivacaine alone $(\mathrm{P}<0.001)$.
Except that, bradycardia was observed in one patient in the dexmedetomidine group, no other adverse effects were observed in either of the groups.

Biswas $S$ et al.(20) studied the role of Dexmedetomidine $(100 \mu \mathrm{g})$ as an adjuvant to levobupivacaine $(35 \mathrm{ml}$ of $0.5 \%)$ in supraclavicular brachial plexus block.They observed that duration of sensory block,motor block, analgesia was longer in Dexmedetomidine group as compared to levobupivacaine alone. They did not observe any side effect during their study in both Dexmedetomidine group and levobupivacaine group.

A meta-analysis was conducted by Daniel M. Popping(3) on various studies using Clonidine doses ranging from 90 to $150 \mu \mathrm{g}$ in brachial plexus block. He found that average duration of motor block and Postoperative analgesia was prolonged in Clonidine group.

A study by Brummett et al.(21) showed that Dexmedetomidine enhances duration of bupivacaine anaesthesia and analgesia of sciatic nerve block in rats without any damage to the nerve.

The histopathological evaluation of these nerve axons and myelin were normal in both control and Dexmedetomidine+bupivacaine groups.

\section{CONCLUSION:}

On the basis of the observation and results of this study, following conclusions are drawn;

a) The onset time of sensory block was faster with Dexmedetomidine compared to Clonidine.

b) The onset of motor block was clinically faster with Clonidine compared to Dexmedetomidine. But the difference in the onset time of motor block was statistically not significant between the two $(p>0.05)$.

c) The duration of sensory block was longer with Dexmedetomidine compared to Clonidine.

d) The duration of motor block was longer with Dexmedetomidine compared to Clonidine.

e) Dexmedetomidine provided longer duration of analgesia compared to Clonidine.

f) Dexmedetomidine causes more sedation than Clonidine.

g) No adverse effects were observed with the addition of Clonidine or Dexmedetomidine as an adjuvant.

To summarise, Dexmedetomidine prolongs the duration of sensory and motor block as well as duration of analgesia without any adverse effects as compared to Clonidine when used as an adjuvant to Bupivacaine in supraclavicular brachial plexus block.

\section{BIBLIOGRAPHY:}

1. Kaur M, Singh P M. Current role of Dexmedetomidine in clinical anaesthesia and intensive care. Anesth Essays Res 2011; 5: 128-33

2. Duma A, Urbanek B, Sitzwohl C, Kreiger A, Zimpfer M, Kapral S. Clonidine as an adjuvant to local anaesthetic axillary brachial plexus block: a randomized, controlled study. Br J Anaesth 2005; 94: 112-16

3. Popping DM, Elia N, Marret E, Wenk M, and Tramer MR. Clonidine as an adjuvant to Local Anaesthetics for Peripheral Nerve and Plexus Blocks. Anesthesiology 2009; 111: 406-15. 
4. Cucchiaro G, Ganesh A. The Effects of Clonidine on Postoperative Analgesia After Peripheral Nerve Blockade in Children. Anesth Analg 2007; 104: 532-7

5. Iskandar $\mathrm{H}$, Guillaume $\mathrm{E}$, Dixmerias $\mathrm{F}$, Binje $\mathrm{B}$, Rakotondriamihary S, Thiebaut R et al. The Enhancement of Sensory Blockade by Clonidine Selectively Added to Mepivacaine After Midhumeral Block. Anesth Analg 2001; 93: 771-5.

6. Raimo V, Juha M, Veijo S, Leena N, Virtanen R. Characterisation of selectivity, specificity and potency of Dexmedetomidine as $\alpha 2$ adrenoceptor agonist. Eur J Pharmacol 1988; 150: 9-14.

7. Keniya VM, Ladi S, Naphade R. Dexmedetomidine attenuates sympathoadrenal response to tracheal intubation and reduces perioperative anaesthetic requirement. Indian J Anaesth 2011; 55: 352-7.

8. Esmaoglu A, Yegenoglu F, Akin A, Turk CY. Dexmedetomidine added to levobupivacaine prolongs. axillary brachial plexus block. Anaesth Analg 2010; 111: 1548-51

9. Obayah GM, Refaie A, Aboushanab O, Ibraheem N, Abdelazees M. Addition of Dexmedetomidine to bupivacaine for greater palatine nerve block prolongs postoperative analgesia after cleft palate repair. Eur J Anaesthesiol 2010; 27: 280-4.

10. Rancourt MP, Albert NT, Cote M, Letourneau DR, Bernard PM. Posterior tibial nerve sensory blockade duration prolonged by adding Dexmedetomidine to ropivacaine. Anesth Analg 2012; 115: 958-62.

11. Swami SS, Keniya VM, Ladi SD, Rao R. Comparison of Dexmedetomidine and Clonidine (a2 agonist drugs) as an adjuvant to local anaesthesia in supraclvicular brachial plexus block: A randomized double-blind prospective study. Indian J Anaesth 2012; 56: 243-9.

12. Ramsay et al - 1974. Controlled sedation with Alaphalonealphadolone. BMJ ii: 656

13. David L. Brown B. Raymond F. The History of Neural Blockade and Pain Management. In: Cousins MJ, Bridenbaugh PO, editors. Neural blockade in clinical anaesthesia and management of pain. 3r ed.Philadelphia: Lippincott-Raven publisher; 1998.p. 3-25.
14. Dalle C, Schneider M, Clergue F, Bretton C, Jirounek P. Inhibition of the $\mathrm{I}(\mathrm{h})$ current isolated peripheral nerve: $\mathrm{A}$ novel mode of peripheral antinociception? Muscle Nerve 2001; 24: 254-61.

15. Casati A, Magistris L, Beccaria P, Cappelleri G, Aldegheri G, Fanelli G. Improving postoperative analgesia after axillary brachial plexus anaesthesia with $0.75 \%$ ropivacaine. A double-blind evaluation of adding Clonidine.

Minerva Anestesiol. 2001 May; 67(5): 407-12.

16. Kosugi T, Mizuta K, Fujita T, Nakashima M, Kumamoto E. High concentrations of dexmedetomidine inhibit compound action potential in frog sciatic nerve without $\alpha$ 2 adrenoceptor activation. Br J Pharmacology 2010; 160: 1662-76.

17. Ammar AS, Mahmoud KM. Ultrasound-guided single injection infraclavicular brachial plexus block using bupivacaine alone or combined with Dexmedetomidine for pain control in upper limb surgery: A prospective randomized controlled trial. Saudi J Anaesth. 2012 Apr; 6(2): 109-14.

18. Kaygusuz K, Kol IO, Duger C, Gursoy S, Ozturk H, Kayacan U, Aydin R, Mimaroglu C. Effects of adding Dexmedetomidine to levobupivacaine in axillary brachial plexus block. Curr Ther Res Clin Exp. 2012 Jun; 73(3): 103-

19. Agarwal S, Aggarwal R, Gupta P. Dexmedetomidine prolongs the effect of bupivacaine in supraclavicular brachial plexus block. J Anaesthesiol Clin Pharmacol. 2014 Jan; 30(1): 36-40.

20. Biswas S, Das RK, Mukherjee G, Ghose T. Dexmedetomidine an adjuvant to levobupivacaine in supraclavicular brachial plexus block: a randomized double blind prospective study. Ethiop J Health Sci. 2014 Jul; 24(3): 203-8.

21. Brummett CM, Amodeo FS, Janda AM, Padda AK, Lydic R. Perineural Dexmedetomidine provides an increased duration of analgesia to a thermal stimulus when compared with a systemic control in a rat sciatic nerve block. Regional anaesthesia pain med. 2010 Sep-Oct; 35(5): 427-31.

\begin{tabular}{|c|c|c|c|c|c|c|}
\hline PARAMETER & $\begin{array}{c}\text { GROUP C } \\
\text { MEAN } \pm \text { SD }\end{array}$ & $\begin{array}{c}\text { GROUP D } \\
\text { MEAN } \pm \text { SD }\end{array}$ & $\mathbf{t}^{*}$ VALUE & P VALUE & $\begin{array}{c}\text { CHI SQUARE } \\
\text { VALUE }\end{array}$ & ASSOCIATION \\
\hline AGE & $33.56 \pm 10.50$ & $33.76 \pm 11.52$ & 0.0703 & 0.944 & NA & NS \\
\hline WEIGHT & $58.86 \pm 5.47$ & $59.6 \pm 3.87$ & 0.6049 & 05476 & NA & NS \\
\hline SEX (M+F) & $21+9$ & $18+12$ & NA & 0.4167 & 1 & NS \\
\hline \multicolumn{7}{|c|}{ Table: 1 Comparison of Demographic variables } \\
\hline
\end{tabular}

NS- Not Statistically Significant; NA- Not Applicable

\begin{tabular}{|c|c|c|c|c|c|}
\hline & $\begin{array}{c}\text { C GROUP } \\
\text { (MEAN } \pm \text { SD) }\end{array}$ & $\begin{array}{c}\text { D GROUP } \\
\text { (MEAN } \pm \text { SD) }\end{array}$ & t VALUE & P VALUE & ASSOCIATION \\
\hline ONSET OF SENSORY BLOCK & $8.53 \pm 0.72$ & $8.18 \pm 0.55$ & 2.1158 & 0.038 & SS \\
\hline ONSET OF MOTOR BLOCK & $9.88 \pm 0.55$ & $10.20 \pm 0.73$ & 1.9176 & 0.0601 & NS \\
\hline \multicolumn{7}{|c|}{ Table: 2 Onset of sensory and motor block } \\
\hline
\end{tabular}

SS- Statistically Significant; 


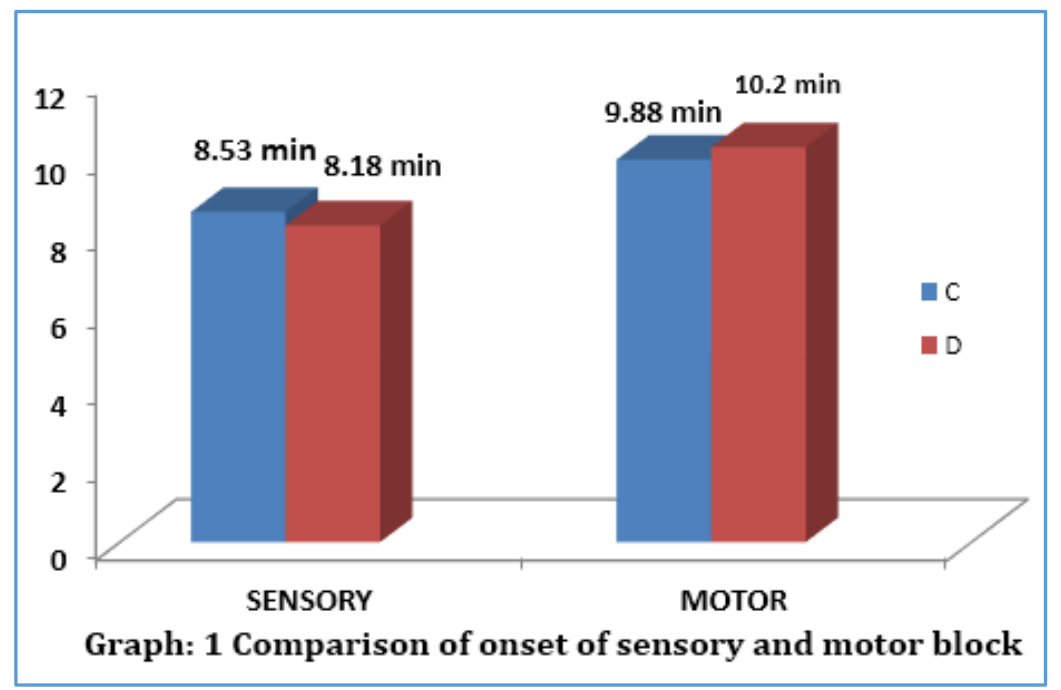

Onset of sensory Block: The onset of sensory block was earlier in Group D compared to group C, which was statistically significant. ( $\mathrm{p}$ value $<0.05$ ).

Onset of motor Block: The difference between the two groups in onset of motor block was not statistically significant. ( $\mathrm{p}$ value $>$ $0.05)$.

\begin{tabular}{|c|c|c|c|c|c|}
\hline & $\begin{array}{c}\text { BC GROUP } \\
\text { (MEAN } \pm \text { SD) }\end{array}$ & $\begin{array}{c}\text { BD GROUP } \\
\text { (MEAN } \pm \text { SD) }\end{array}$ & t VALUE & P VALUE & ASSOCIATION \\
\hline DURATION OF SENSORY BLOCK & $331.43 \pm 6.693$ & $395.93 \pm 12.55$ & 24.83 & $<0.05$ & SS \\
\hline DURATION OF MOTOR BLOCK & $271.43 \pm 6.69$ & $335.93 \pm 12.55$ & 24.07 & $<0.05$ & SS \\
\hline DURATION OF ANALGESIA & $407.06 \pm 10.9$ & $497.06 \pm 10.90$ & 31.97 & $<0.001$ & SS \\
\hline \multicolumn{6}{|c|}{ Table: 3 Duration of sensory \& motor block and analgesia } \\
\hline
\end{tabular}

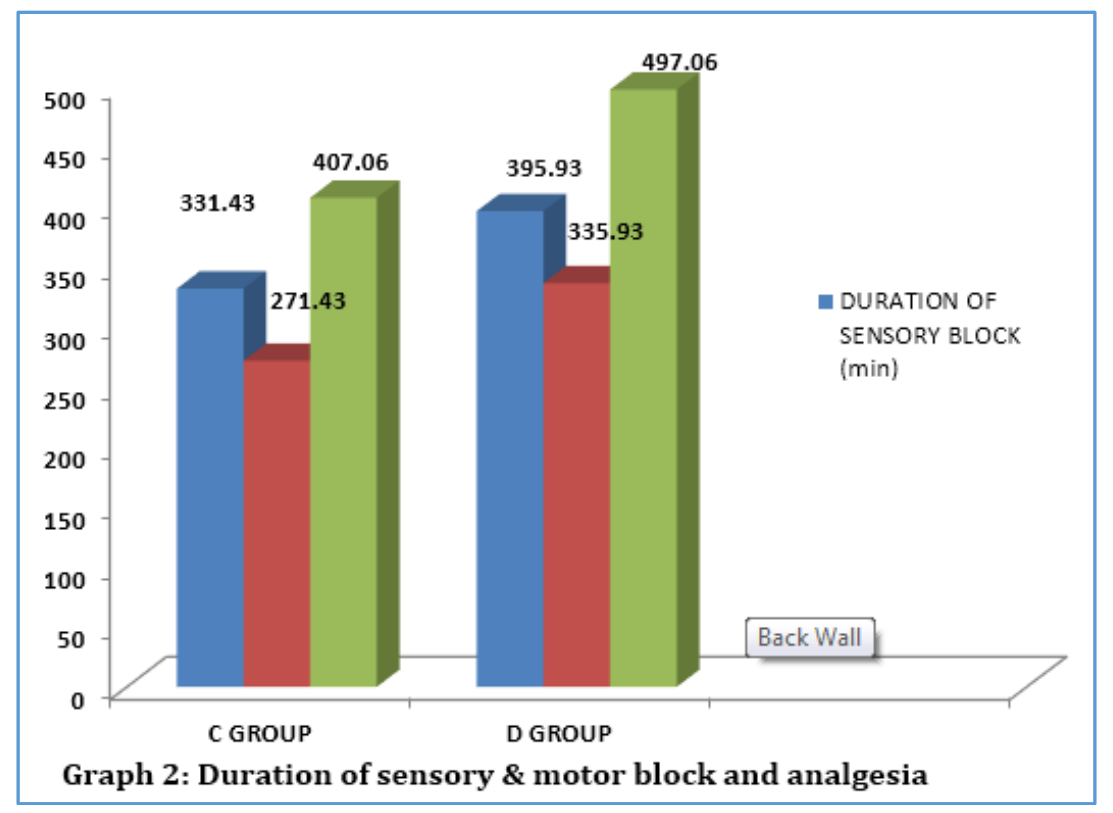

The duration of sensory block, motor block and analgesia was prolonged in group D in comparison with group C which was statistically significant. (P value $<0.05$ )

Comparison of sedation score between group C and group D;

\begin{tabular}{|c|c|c|c|c|c|}
\hline & \multicolumn{2}{|c|}{ Group C } & \multicolumn{2}{c|}{ Group D } & \multirow{2}{*}{ p value } \\
\cline { 2 - 5 } & Mean \pm SD & Median & Mean \pm SD & Median & \\
\hline Sedation Score & $2.13 \pm 0.35$ & 2.0 & $2.93 \pm 0.25$ & 3.0 & $<0.001$ \\
\hline Table 4: Comparison of sedation score between group C and group D \\
\hline
\end{tabular}

The difference between the two groups was statistically significant ( $p$ value $<0.001$ ). 


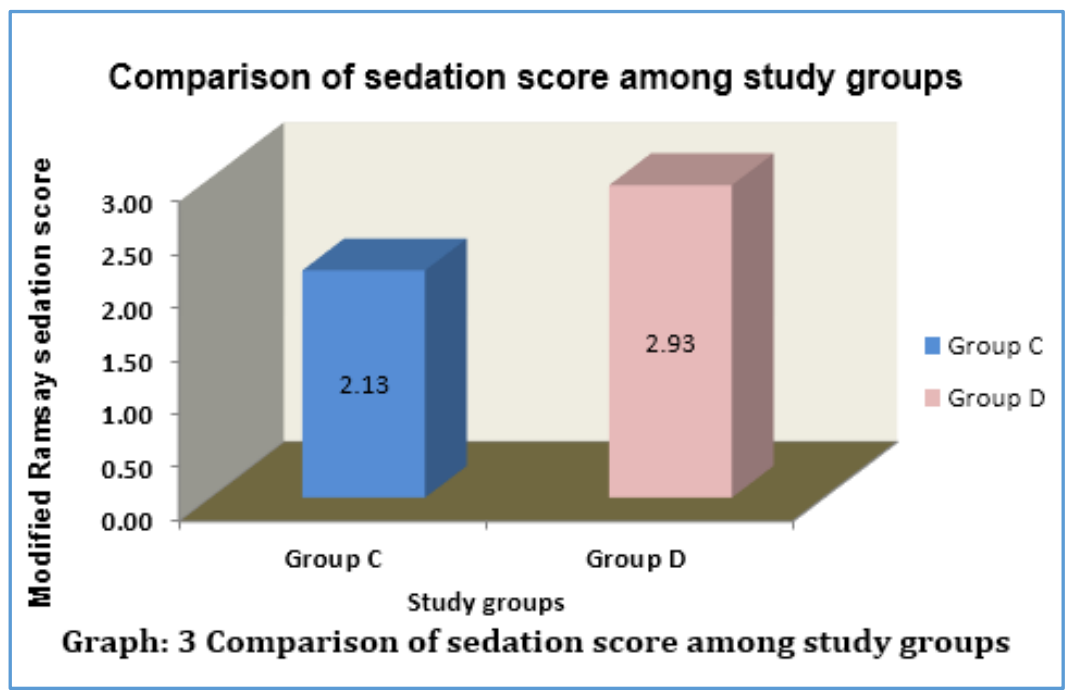

\begin{tabular}{|c|c|c|c|c|}
\hline \multirow{2}{*}{ Time of assessment } & \multicolumn{2}{|c|}{ Mean \pm SD } & \multirow{2}{*}{ p Value } & \multirow{2}{*}{ Significance } \\
\cline { 2 - 5 } & Group C & Group D & & \\
\hline $0(\mathrm{~min})$ & $75.16 \pm 6.01$ & $78.00 \pm 5.81$ & 0.067 & $\mathrm{NS}$ \\
\hline $5(\mathrm{~min})$ & $75.50 \pm 5.81$ & $77.30 \pm 5.55$ & 0.224 & $\mathrm{NS}$ \\
\hline $15(\mathrm{~min})$ & $75.50 \pm 5.81$ & $77.30 \pm 5.55$ & 0.224 & $\mathrm{NS}$ \\
\hline $30(\mathrm{~min})$ & $75.50 \pm 5.92$ & $77.06 \pm 5.60$ & 0.298 & $\mathrm{NS}$ \\
\hline $60(\mathrm{~min})$ & $75.50 \pm 6.40$ & $76.90 \pm 5.55$ & 0.369 & $\mathrm{NS}$ \\
\hline $2(\mathrm{hrs})$ & $75.40 \pm 6.01$ & $76.33 \pm 5.67$ & 0.540 & $\mathrm{NS}$ \\
\hline $3(\mathrm{hrs})$ & $75.46 \pm 6.25$ & $76.50 \pm 5.80$ & 0.506 & $\mathrm{NS}$ \\
\hline $4(\mathrm{hrs})$ & $75.73 \pm 6.16$ & $77.13 \pm 5.46$ & 0.355 & $\mathrm{NS}$ \\
\hline $5(\mathrm{hrs})$ & $75.63 \pm 6.16$ & $77.43 \pm 5.45$ & 0.235 & $\mathrm{NS}$ \\
\hline $6(\mathrm{hrs})$ & $76.50 \pm 6.04$ & $77.26 \pm 5.34$ & 0.607 & $\mathrm{NS}$ \\
\hline \multicolumn{4}{|l|}{ Table 5: Comparison of Pulse rate between two groups } \\
\hline
\end{tabular}

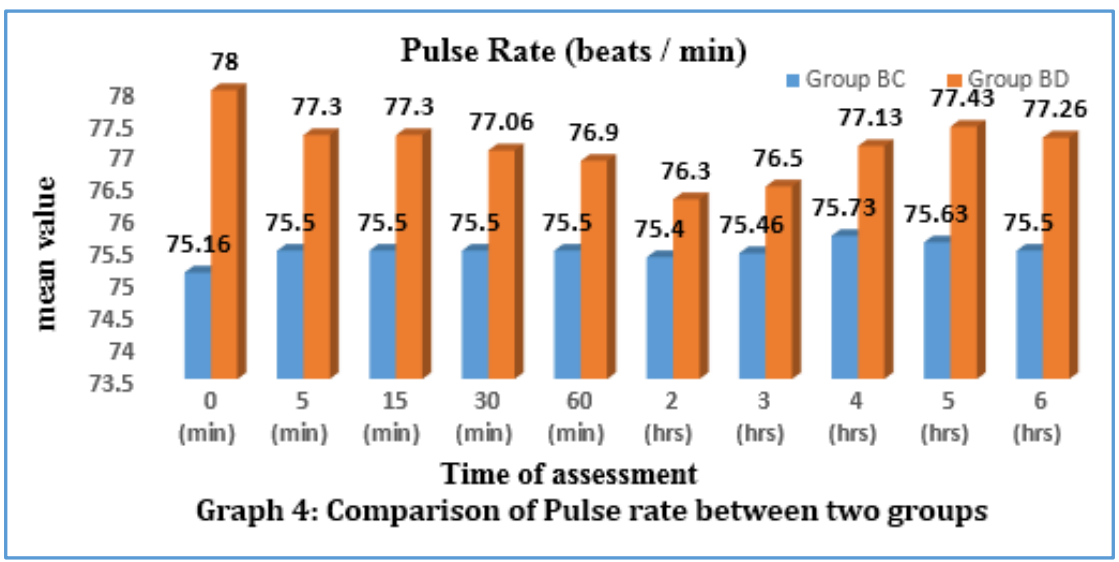

\begin{tabular}{|c|c|c|c|c|}
\hline \multirow{2}{*}{ Time of assessment } & \multicolumn{2}{|c|}{ Mean \pm SD } & \multirow{2}{*}{ P Value } & \multirow{2}{*}{ Significance } \\
\cline { 2 - 5 } & Group C & Group D & & NS \\
\hline $\mathbf{0}$ (min) & $118.20 \pm 10.33$ & $121.53 \pm 6.76$ & 0.145 & $\mathrm{NS}$ \\
\hline $\mathbf{5}$ (min) & $117.96 \pm 10.19$ & $120.73 \pm 6.37$ & 0.211 & $\mathrm{NS}$ \\
\hline $\mathbf{1 5}$ (min) & $118.06 \pm 9.34$ & $119.80 \pm 6.46$ & 0.404 & $\mathrm{NS}$ \\
\hline $\mathbf{3 0}$ (min) & $118.33 \pm 9.93$ & $119.26 \pm 6.44$ & 0.668 & $\mathrm{NS}$ \\
\hline $\mathbf{6 0}$ (min) & $118.00 \pm 10.03$ & $118.60 \pm 6.66$ & 0.785 & $\mathrm{NS}$ \\
\hline $\mathbf{2}$ (hrs) & $117.90 \pm 10.29$ & $118.16 \pm 6.61$ & 0.907 & $\mathrm{NS}$ \\
\hline $\mathbf{3}$ (hrs) & $117.93 \pm 10.29$ & $117.60 \pm 6.35$ & 0.881 & $\mathrm{NS}$ \\
\hline $\mathbf{4}$ (hrs) & $118.03 \pm 9.84$ & $117.73 \pm 6.63$ & 0.890 & $\mathrm{NS}$ \\
\hline $\mathbf{5}$ (hrs) & $117.83 \pm 10.0$ & $118.06 \pm 6.59$ & 0.916 & \multicolumn{1}{|c|}{} \\
\hline $\mathbf{6}$ (hrs) & $117.80 \pm 9.90$ & $118.06 \pm 6.63$ & 0.905 & \\
\hline Table 6: Comparison of Systolic Blood Pressure between two groups \\
\hline
\end{tabular}




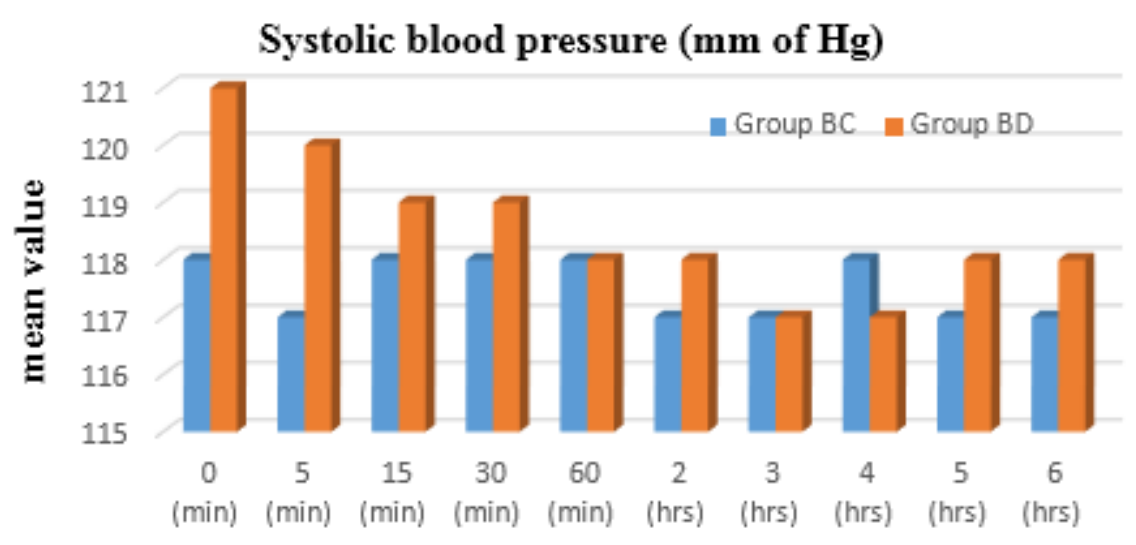

Time of assessment

Graph 5: Comparison of Systolic Blood Pressure between two groups

\begin{tabular}{|c|c|c|c|c|}
\hline \multirow{2}{*}{$\begin{array}{c}\text { Time of } \\
\text { assessment }\end{array}$} & \multicolumn{2}{|c|}{ Mean \pm SD } & \multirow{2}{*}{ P Value } & \multirow{2}{*}{ Significance } \\
\hline & Group C & Group D & & \\
\hline 0 (min) & $76.63 \pm 7.48$ & $77.73 \pm 4.51$ & 0.490 & NS \\
\hline 5 (min) & $76.30 \pm 6.90$ & $77.06 \pm 4.54$ & 0.616 & NS \\
\hline 15 (min) & $76.06 \pm 6.54$ & $75.93 \pm 4.40$ & 0.928 & NS \\
\hline $30(\mathrm{~min})$ & $76.43 \pm 6.72$ & $75.46 \pm 4.48$ & 0.513 & NS \\
\hline $60(\mathrm{~min})$ & $76.66 \pm 6.21$ & $75.00 \pm 4.12$ & 0.227 & NS \\
\hline 2 (hrs) & $76.66 \pm 6.21$ & $75.00 \pm 4.12$ & 0.227 & NS \\
\hline 3 (hrs) & $76.36 \pm 6.84$ & $74.13 \pm 4.09$ & 0.130 & NS \\
\hline $4 \quad$ (hrs) & $76.36 \pm 6.84$ & $74.13 \pm 4.09$ & 0.130 & NS \\
\hline 5 (hrs) & $75.83 \pm 6.65$ & $74.26 \pm 3.88$ & 0.268 & NS \\
\hline 6 (hrs) & $76.03 \pm 6.48$ & $74.46 \pm 3.91$ & 0.260 & NS \\
\hline
\end{tabular}

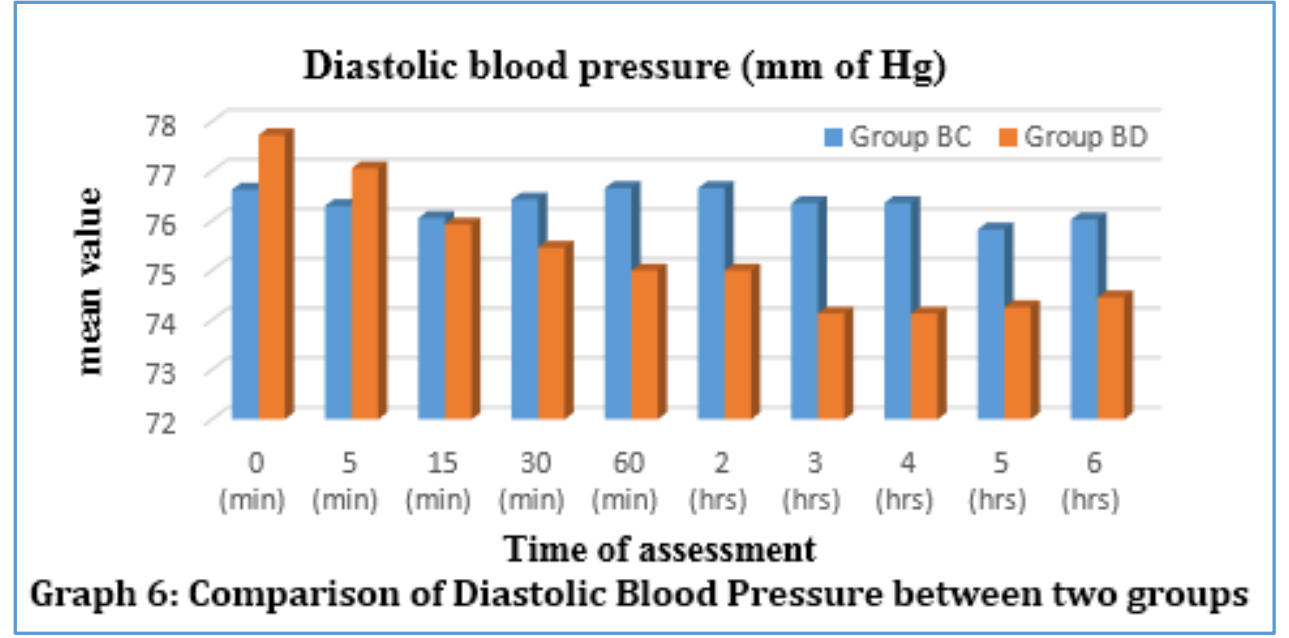

\begin{tabular}{|c|c|c|c|c|}
\hline \multirow{2}{*}{$\begin{array}{c}\text { Time of } \\
\text { Assessment }\end{array}$} & \multicolumn{2}{|c|}{ Mean \pm SD } & \multirow[b]{2}{*}{ P Value } & \multirow[b]{2}{*}{ Significance } \\
\hline & $\begin{array}{c}\text { Bupivacaine- } \\
\text { Clonidine }\end{array}$ & $\begin{array}{c}\text { Bupivacaine- } \\
\text { Dexmedetomidine }\end{array}$ & & \\
\hline $0 \quad(\min )$ & $98.86 \pm 0.34$ & $98.90 \pm 0.30$ & 0.630 & NS \\
\hline $5 \quad(\min )$ & $98.86 \pm 0.34$ & $98.90 \pm 0.30$ & 0.630 & NS \\
\hline $15(\min )$ & $98.70 \pm 0.46$ & $98.76 \pm 0.43$ & 0.603 & NS \\
\hline $30(\min )$ & $98.66 \pm 0.47$ & $98.60 \pm 0.47$ & 0.622 & NS \\
\hline 60 (min) & $98.66 \pm 0.47$ & $98.60 \pm 0.47$ & 0.622 & NS \\
\hline 2 (hrs) & $98.66 \pm 0.47$ & $98.60 \pm 0.47$ & 0.622 & NS \\
\hline 3 (hrs) & $98.53 \pm 0.50$ & $98.73 \pm 0.44$ & 0.105 & NS \\
\hline 4 (hrs) & $98.53 \pm 0.50$ & $98.74 \pm 0.44$ & 0.105 & NS \\
\hline 5 (hrs) & $98.73 \pm 0.37$ & $98.70 \pm 0.46$ & 0.232 & NS \\
\hline 6 (hrs) & $98.73 \pm 0.44$ & $98.90 \pm 0.30$ & 0.857 & NS \\
\hline
\end{tabular}




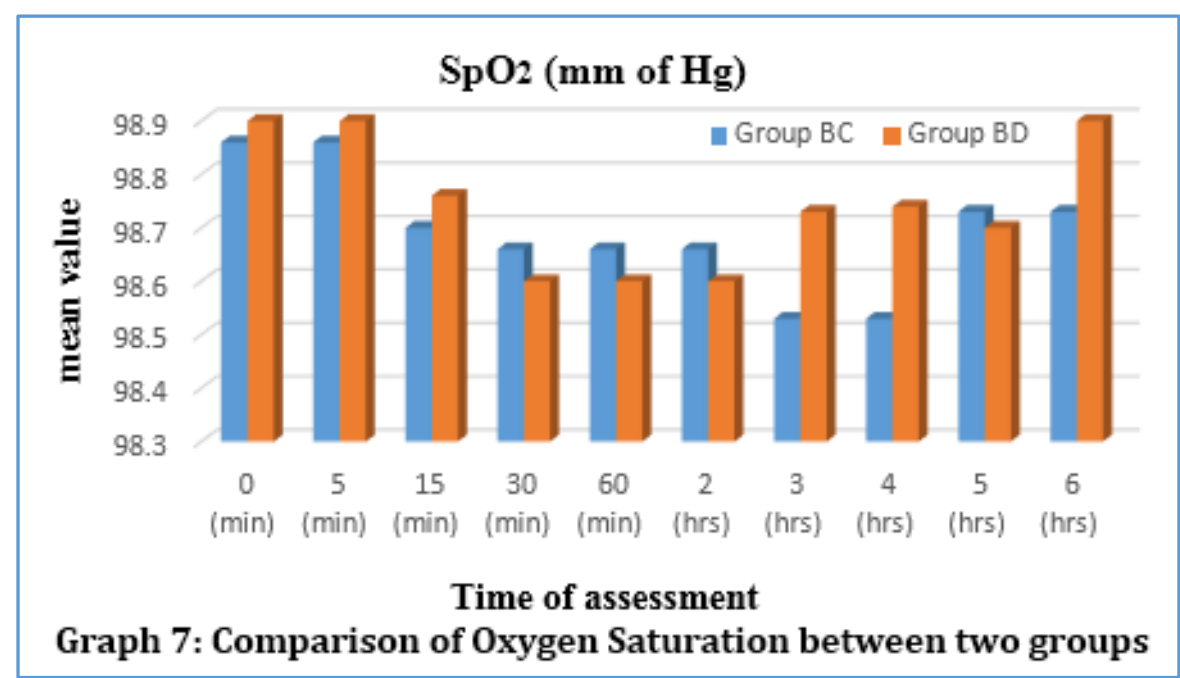

There was no statistically significant difference in pulse rate, systolic blood pressure, diastolic blood pressure and oxygen saturation between the two groups. 